\title{
Teleología y Trabajo: Finalidad subjetiva en la Lógica de Hegel y el Proceso de trabajo en Marx
}

\author{
Teleology and Work: Subjective purpose in Hegel's Logic and Marx's Work \\ Process
}

Oscar Pérez Portales ${ }^{1}$

\begin{abstract}
Resumen
La explicación del proceso de trabajo en la formulación expuesta en El Capital implica una síntesis de la concepción de objetividad en el pensamiento de Marx; que rompe con el iusnaturalismo de la Economía Política Clásica. No obstante, su estructuración dialecticopráxica del trabajo como finalidad en la relación sujeto- objeto fue objeto de una fundamentación contradictoriamente re-naturalizadora. La teleología de Marx expuesta en El Capital se sustenta en una asunción crítica de la teleología hegeliana. En aquella la finalidad subjetiva tiene por base la acción subjetiva reducida por las fuerzas de la exterioridad natural superior. En Marx, por el contrario, se observa una renovada comprensión del proceso de trabajo, con una objetividad que comprende el momento subjetivo y la transformación de la exterioridad como partes del proceso de trabajo. No obstante, el análisis de esa diferenciación, frente a la teleología de Hegel, puede servir de base a una visualización de los elementos lógicos que contesten las interpretaciones que fundamentan de forma exteriorisante y re-naturalizadora el proceso de trabajo como finalidad.
\end{abstract}

Palabras Llaves: Teleología. Lógica. Hegel. Marx

\section{Abstract}

The explanation of the work process in the formulation set forth in The Capital implies a synthesis of the conception of objectivity in Marx's thinking; that breaks with the iusnaturalism of the Classic Political Economy. However, its dialectico-praxis structuring of work as a purpose in the subject-object relationship was the object of a contradictorily re-naturalizing foundation. Marx's teleology exposed in Capital is based on a critical assumption of Hegelian teleology. In that, the subjective purpose is based on the subjective action reduced by the forces of superior natural exteriority. In Marx, on the contrary, there is a renewed understanding of the work process, with an objectivity that includes the subjective moment and the transformation of exteriority as parts of the work process. However, the analysis of this differentiation, in front of Hegel's teleology, can serve as a basis for a visualization of the logical elements that answer the interpretations that base the work process as an objective and re-naturalize.

Keywords: Teleology. Logical. Hegel. Marx.

\footnotetext{
${ }^{1}$ Master en Filosofía PUCRS. Investiga PUCRS. Doctorando en Filosofía PUCRS. Bolsista CAPES/PROEX. Profesor - Universidad de Oriente (Cuba).

E-mail: oscarahportales2487@gmail.com
} 


\section{Introducción}

El presente trabajo se orienta a la exploración de los nexos de la Teleología propia de la Lógica de Hegel y la teoría del Proceso de Trabajo expuesta por Marx en el Capítulo V del Libro I de EL Capital. Ante la bastedad que tal tratamiento implica nos centraremos en situar esos nexos en la valoración de la concepción de Finalidad subjetiva expuesta en la Teoría del objeto dentro del decurso reflexivo de La Doctrina del Concepto de La Ciencia de la Lógica. En tal acápite Hegel desarrolla la teleología externa del trabajo dentro de la Lógica, con importantes consecuencias para la comprensión de la relación entre sujeto y objeto. La finalidad abrirá paso allí al momento de realización no mecánica del concepto en la objetividad en un estatus que no depende de una causalidad eficiente. Así mismo, este momento afecta y disuelve la frontera entre un objeto exterior y la subjetividad abriendo paso a un entendimiento auto-poiético de la transformación de la realidad natural.

Si son evidentes las diferencias de Marx con esta teleología, incuestionable es su papel en la comprensión marxiana del proceso de trabajo. La teleología se sustenta en una comprensión del trabajo como haciendo parte de una realidad natural que transforma y se transforman así misma. El trabajo como valor de uso de la fuerza de trabajo asume una lógica de gasto y transformación de energía física. Al mismo tiempo la finalidad del trabajo es un hecho social, por ello la subjetividad es un momento objetivo en tanto depende del trabajo acumulado y de la relación con el otro.

No obstante, la simple diferenciación del idealismo hegeliano no puede negar la deuda marxiana con su entendimiento práxico de la poiésis del trabajo. Varios enfoques marxistas han afirmado el materialismo marxiano volviendo a una suerte de justificación causal del trabajo como proceso de modificación del objeto natural externo. Lo que sitúa a la subjetividad como resultado reflejo de una objetividad que le es exterior. Esta tradición asienta una interpretación, que alejada de la praxis de Marx, le es adjudicada. A partir de la cual se critica el carácter material del proceso de trabajo en Marx, como es el caso de la interpretación de Habermas. Es por ello que una revisión del carácter práxico de la compresión del trabajo en Marx tiene 
punto inicial en una valoración de sus nexos con la teleología hegeliana. A fin de evidenciar la estructura reflexiva de la comprensión práctica del proceso de trabajo.

Precisamente se sigue aquí el objetivo de valorar los nexos y rupturas de la comprensión del proceso de trabajo con la concepción de finalidad subjetiva. Para tanto primeramente desarrollaremos una re-construcción de la concepción de Finalidad Subjetiva en la Doctrina del Concepto. Punto de partida este de una exploración valorativa de teoría del Proceso de trabajo en el Capital.

\section{Finalidad subjetiva y trabajo en la lógica de Hegel}

La finalidad es un núcleo central en el momento de desarrollo de la razón dentro de la lógica hegeliana. La finalidad como categoría lógica expone un paso superior en el proceso de determinación del concepto. En ella no se trata más de un traspaso o de un accidente que la convierte en efecto de este. El fin es causa en sí mismo y efecto que en su externación es la identidad de esa causa. Tal movimiento ha sucedido a la explicitación del mecanismo y el quimismo como instancia limitadas del desarrollo del concepto en la realidad externa. Frente estos la teleología viene a ocupar un papel de enlace transicional en el cual el concepto alcanza un nivel de su realización práctica, sin el cual no puede determinarse en cuanto tal. La finalidad es el medio de volverse práctico del concepto que se relaciona con la exterioridad que debe determinar. Apunta ya de inicio Hegel en la introducción del capítulo tercero dedicado a la Teleología:

Donde es percibida la conformidad a fines, se asume un entendimiento como autor de la misma, por tanto, para el fin se exige la existencia propia, libre, del concepto. La teleología es contrapuesta principalmente al mecanismo en el cual la determinación puesta en el objeto, esencialmente como externa, es un tipo de determinación en la cual no se manifiesta autodeterminación alguna. ${ }^{2}$

El momento de relación del concepto con la exterioridad que inicia la teleología es aquel en que este relacionarse es orientado a la autodeterminación. Las causas y efectos aquí están determinadas por la finalidad como movimiento no

\footnotetext{
${ }^{2}$ HEGEL Georg Wilhelm Friedrich. Ciencia Da Lógica: 2. A Doutrina da Essencia. Trad. Cristhian G. Iber; Federico Orsini. Petropolis, Rj: Vozes; Bragança Paulista, Sp: Editora Universitária São Francisco, 2017, p. 214.
} 


\section{4 | Opinião Filosófica, V. 11, Dossiê - Teoria do Objeto na Lógica de Hegel}

eficiente de la racionalidad a la exterioridad. La causa eficiente del mecanismo es puesta en análisis frente a la causa final. Este análisis es crucial para una compresión práxica de la realidad, es decir superadora de las construcciones deterministas y fatalistas. El concepto aquí debe encontrar el momento de su libertad y este es el de la finalidad. Base reflexiva que tendrá importantes consecuencias, por ejemplo, en la contestación marxiana del iusnaturalismo de la economía política inglesa. Donde los procesos de trabajo con explicados desde un determinismo mecánico que regula a los productores. Frente a cuya determinación externalizada del proceso de trabajo se responde desde una comprensión social que implica que como proceso histórico puede ser modificado. Sin esta perspectiva lógica de anteposición de la especificidad de la causa final de la teleología no puede entenderse la basa reflexiva y la dialéctica del análisis de Marx. Hegel es taxativo cuando afirma: "La antinomia del fatalismo con el determinismo y de la libertad concierne igualmente a la oposición del mecanismo y de la teleología; pues el libre es el concepto en su existencia"3.

Hegel critica a la metafísica antecedente el haber construido una imagen de lo real a la que adecuar el concepto. Lo que motiva entonces la necesaria determinación de la verdad de concepto mecánico y de finalidad. En tanto ambos no pueden por sí mismo ser verdaderos al mismo tiempo. Si las causas del mundo objetivo son eficientes desdoblamientos mecánicos no puede sostenerse que el carácter verdadero de este sea el desarrollo de finalidades. En la finalidad, opuesta a la externalidad del mecanismo, el contenido presupone un concepto que es determinante. Su condición de en sí y para sí lo diferencia de la relación por esto lo separa de la necesidad que determina el mecanismo. Hegel no en tanto, ironiza que la determinación de la finalidad no puede ser la de una voluntad o entendimientos orientados a fines contingentes. Es decir, la finalidad de la teleología no puede estar determinada por un actuar que se ajusta a la exterioridad. Por el contrario, la teleología está determinada por tener dentro de ella el principio de la libertad que esta sustraído de la determinación externa del mecanismo.

\footnotetext{
3 HEGEL Georg Wilhelm Friedrich. Ciencia Da Lógica: 2. A Doutrina da Essencia. Trad. Cristhian G. Iber; Federico Orsini. Petropolis, Rj: Vozes; Bragança Paulista, Sp: Editora Universitária São Francisco, 2017, p. 213.
} 
Aquellos que se presenta como quimismo es tomado en conjunto como el mecanismo en la medida en que la finalidad es el concepto en la existencia libre y se le contrapone en general la falta de libertad del mismo, su ser sumergido en la exterioridad... ${ }^{4}$

Como señala Iber aquí el concepto supone una instancia práctico-poiética, en tanto el concepto se auto-determina desde la subjetividad 5 . No es además una capacidad de juicio exterior que indaga la universalidad conceptual en el interior de objetos particulares o su reducción a tal. Es una mediación entre que se encamina a la consecución de la universalidad del concepto en la singularidad del objeto al que se orienta. A partir de este entendimiento podríamos apreciar como la finalidad supone un momento práctico de dialéctica entre el objeto y el concepto. Esto es, entre la subjetividad que pone el concepto y el objeto. No hay una exterioridad, mecánica, natural que determina el fin, en este momento el concepto esta autodeterminado. Mas esa relación entre mecanismo, quimismo y finalidad es un paso reflexivo que debe ser explorado y que nos encamina al examen de la finalidad dentro de los procesos de trabajo.

En este momento queda evidente la centralidad de la categoría finalidad en la lógica del concepto que implica un desarrollo de la racionalidad páctico- poiética. Determinada por el movimiento del concepto, en la objetividad esta se define en la oposición entre subjetividad y objeto. El concepto tiene ahora en su determinación la exterioridad. Ello en un proceso en que sale de si, mas tiene su unidad en este proceso de extrañarse de sí mismo. La finalidad tiene su especificidad lógica en el hecho de que se preserva en el otro, no pasa al otro, se conserva. Idea de finalidad de esencia autopoiética que es la base de la teleología del trabajo.

La finalidad es, por tanto, el concepto subjetivo, como esfuerzo e impulso esenciales par se poner exteriormente. En eso, ella esta sustraída al pasar. Ella no es ni una fuerza que se externa, ni una substancia y una causa que se manifiesta en los accidentes en los efectos. ${ }^{6}$

\footnotetext{
4 HEGEL Georg Wilhelm Friedrich. Ciencia Da Lógica: 2. A Doutrina da Essencia. Trad. Cristhian G. Iber; Federico Orsini. Petropolis, Rj: Vozes; Bragança Paulista, Sp: Editora Universitária São Francisco, 2017, p. 214.

5 IBER, A teoría do objeto na Lógica de Hegel. POA, 2019/2, 07/10/2019. Teleologia I. Introdução à teleología. Observação prévia, p. 2.

${ }^{6}$ HEGEL Georg Wilhelm Friedrich. Ciencia Da Lógica: 2. A Doutrina da Essencia. Trad. Cristhian G. Iber; Federico Orsini. Petropolis, Rj: Vozes; Bragança Paulista, Sp: Editora Universitária São Francisco, 2017, p. 221.
} 
Las implicaciones de esta lógica para la comprensión de la naturaleza del proceso de trabajo son evidentes cuando se analiza el carácter paradoxal de esta suposición. Desde esta comprensión se intuye el camino para una comprensión desde la praxis de la finalidad y para la superación de las determinaciones exteriorizantes del trabajo como finalidad. De una parte, se entiende que aquí la finalidad no es el fuero de una simple determinación del entendimiento que ha sido ironizado por Hegel. Si no un proceso de externalización determinante, en tanto el ponerse es su realización. La finalidad no es el espacio de una subjetividad opuesta y determinada por una exterioridad objetual, como entendimiento que se reafirma en un objeto. La finalidad en su estatus autopoiético, implica su anterioridad y su subsistir en el objeto creado que no le es más externo. En la lógica del trabajo el producto de este es un objeto fruto de la subjetividad que al producir no se determina exteriormente si no que subsiste en la relación exterior. Ya veremos cómo Marx diferencia el gasto de energía de un animal, del realizado por el hombre, asumiendo en uno un mecanismo y en el otro el desarrollo de la finalidad. El proceso de trabajo no puede comprenderse fuera de este marco auto-poiético. El trabajo no puede ser una finalidad determinada exteriormente por el objeto. La diferenciación subordinante entre objeto externo y subjetividad finalista aquí reproduciría un marco de causalidad-efecto que ha sido superado en la teleología. No hay expresión más fiel que la que señala Hegel:

La finalidad puede, ciertamente, ser determinada también como fuerza y causa, mas esas expresiones completan a penas un lado incompleto del significado de la finalidad, si ellas deben ser enunciadas de la finalidad conforme la verdad de esa, así ellas pueden serlo solamente de un modo que suprasume su conceptocomo una fuerza que solicita a sí misma para la externalización, como una causa que es causa de sí misma o cuyo efecto es inmediatamente la causa. 7

A pesar de las diferencias de las teleologías desde las cuales se expresan, podemos evidenciar las consecuencias de esta comprensión en la explicitación del proceso de trabajo en Marx. Diversas interpretaciones abundan en la diferenciación de la antropología desde la cual se sitúa Marx. Un materialismo relacional que

\footnotetext{
7 HEGEL Georg Wilhelm Friedrich. Ciencia Da Lógica: 2. A Doutrina da Essencia. Trad. Cristhian G. Iber; Federico Orsini. Petropolis, Rj: Vozes; Bragança Paulista, Sp: Editora Universitária São Francisco, 2017, p. 221.
} 
comprende el trabajo como fuerza práctica de transformación del medio y de sí. No obstante, más allá de la anteposición del materialismo marxiano, es esencial entender la impronta reflexiva hegeliana en aquel. El trabajo está situado en su teleología desde esta base. Ello supone que el proceso de trabajo es la praxis del momento conceptual y exterior de transformación del objeto. Mas en una dialéctica que no es más la de un sujeto opuesto a un objeto que le es externo. El trabajo en cuanto finalidad es un plexo praxico que implica la reflexión y práctica transformadora. Sin esta referencia algunas comprensiones marxistas tienden a interpretar al propio trabajo como una externalidad objetual, determinante de la subjetividad. Es decir, lo sitúan en una lógica de relación causa efecto propia del mecanismo que ha suprimido el momento poiético ${ }^{8}$.

La potencia de la teoría Marxiana viene de contestar tal visión externalizada del trabajo como objeto determinante. Solo un proceso histórico y praxico de creación práctica autopoéitica puede ser alterado, regulado, transformado. El fenómeno del trabajo como finalidad histórica determinada, solo puede ser entendido desde una lógica reflexiva que reconozca su especificidad praxica, superadora de la dicotomía entre subjetividad y objeto externo. Más allá de la señalada comparación que Iber coloca sobre la sobre determinación que realiza el concepto en el idealismo hegeliano, si el proceso de trabajo en Marx no es valorado desde una comprensión dialéctica de la finalidad como espacio de desarrollo y subsistencia de la subjetividad en el objeto, puede derivarse a comprensiones de tipo externalista. Que suponen al trabajo como actividad en la que la subjetividad transforma al objeto que le es exterior. Volveríamos a una dinámica externa de la cual Hegel ya ha colocado sus límites en el mecanismo. Las disimiles interpretaciones en este marco reductivo de la obra de Marx condujeron en varios pensamientos a la reproducción del iusnaturalismo que su obra niega.

Si el aspecto de conformidad a fines es atribuido a un entendimiento, como fue indicado anteriormente, entonces, en ese caso, se lleva en consideración lo determinado del contenido. Mas el entendimiento debe ser tomado en general como lo racional en

\footnotetext{
${ }^{8}$ KOHAN, Nestor. Marx en su (Tercer) mundo. Habana: Ciencias Sociales, 2003, p. 140.
} 


\section{8 | Opinião Filosófica, V. 11, Dossiê - Teoria do Objeto na Lógica de Hegel}

su existencia. El manifiesta racionalidad porque es el concepto concreto que retiene la diferencia objetiva en su unidad absoluta. ${ }^{9}$

Hegel asume que el entendimiento y su desenvolvimiento reflexivo expresa la concreción del concepto. Es evidente que el idealismo hegeliano a trasladado las estructuras racionales de la lógica a la práctica como actividad creadora ${ }^{10}$. Mas el hecho de que la estructura que exprese la finalidad sea la del silogismo tiene importantes consecuencias. La propia construcción silogística nos permite entender que el proceso de trabajo no puede ser explicitado en términos de una subjetividad que aprehende un objeto exterior. Tal exterioridad podría y ha sido extendida al propio trabajo como exterioridad mecánica que determina al sujeto. Como coloca Hegel ello es un silogismo por tanto no hay un singular antepuesto a un particular. Si no que implica que el momento de afectación externa de la subjetividad por el objeto solo es un momento que está determinado por la realización de la universalidad que sostiene la subjetividad. Dice Hegel:

En segundo lugar, porque su determinación tiene la forma de la indiferencia objetiva, ella tiene la figura de una presuposición y su finitud consiste, según ese lado, en el hecho de que ella tiene un mundo objetivo, mecánico o químico, delante de si, con el cual su actividad se relaciona como con algo presente; su actividad autodeterminante es, así, en su identidad, inmediatamente externa sí dentro de misma, y tanto reflexión dentro de sí en cuanto reflexión para afuera. ${ }^{11}$

No obstante, la finalidad subjetiva que coloca Hegel es la subjetividad del productor libre, el Robinson Crusoe que cambia el mundo a partir de su finalidad ${ }^{12}$. El entendimiento unitario de la sociedad civil reproduce la concepción smithiana del trabajo y la finalidad. Marco reflexivo que produce el paradigma mecánico que domina el contexto hegeliano, que supone la reducción de la naturaleza como

\footnotetext{
9 HEGEL Georg Wilhelm Friedrich. Ciencia Da Lógica: 2. A Doutrina da Essencia. Trad. Cristhian G. Iber; Federico Orsini. Petropolis, Rj: Vozes; Bragança Paulista, Sp: Editora Universitária São Francisco, 2017, p. 221.

${ }^{10}$ IBER, A teoría do objeto na Lógica de Hegel. POA, 2019/2, 07/10/2019. Teleologia I. Introdução à teleología. Observação prévia, p. 2.

${ }^{11}$ HEGEL Georg Wilhelm Friedrich. Ciencia Da Lógica: 2. A Doutrina da Essencia. Trad. Cristhian G. Iber; Federico Orsini. Petropolis, Rj: Vozes; Bragança Paulista, Sp: Editora Universitária São Francisco, 2017, p. 222.

${ }^{12}$ LUKACS, Georg. El Joven Hegel. Y los problemas del capitalismo. Trad. Manuel Sacristan. Barcelona: Ediciones Grijalbo, 1970, p. 360.
} 
exterioridad ${ }^{13}$. La finalidad como universal elemento de desarrollo del concepto precisa la mediación de un objeto el medio en su relación con la singularidad. La subordinación al concepto hace que la objetividad de la teleología este situada en un afuera de la relación de trabajo. Ello implica que la estructura silogística mantiene en el esquema exterior del trabajo la idea de una producción simple. La finalidad subjetiva tiene todavía una existencia verídicamente extra-mundana en tanto se contrapone a un todo mecánico y químico sin finalidad ${ }^{14}$. Esto es, la finalidad enfrentada al mecanismo no es capaz de comprender procesos de trabajos en los que la disyunción mecanismo quimismo esta subsumida en una teleología de las relaciones sociales de trabajo. Ahí es donde radica el punto de partida de Marx.

La finalidad es un poner inmediato de un contenido interno que supone un mundo objetivo exterior. Mas este inicial poner del contenido de la finalidad precisa ser suprasumido en la relación entre el sujeto y el objeto externo. El primer paso de la suprasunción de la finalidad es la determinación de un objeto que se supone medio de la realización de la finalidad. Mas el proceso de determinación del medio hace que la finalidad se silogice con la objetividad. Iber cuestiona que en la lógica de Hegel la objetividad está en la finalidad que se encuentra consigo misma y por ello con la objetividad. Antepone a esto la visión de Marx en que la objetividad no se encuentra en el momento subjetivo de la finalidad, o en su realización en el sentido de coincidencia o realización externa de la subjetividad. Por el contrario, la objetividad está situada en las dinámicas de trabajo que en su actuación producen la finalidad. Por ello se distancia de Hegel cuando en su teleología "a exterioridad indiferente es la determinación fundamental del mundo" donde el concepto absoluto produce el mundo exterior. Es partir de estos elementos que a continuación podemos valorar la relación entre la concepción hegeliana de finalidad subjetiva y la comprensión marxiana del proceso de trabajo expuesta en el Capítulo V del Libro I del Capital.

${ }_{13}$ ORSINI, Federico. A astúcia da razão, ou seja, a 'filosofia da técnica' de Hegel. POA: 28/10/2019, p. 2.

14 IBER, Christian. A teoria do objeto na Lógica de Hegel Teleologia III. A teoria hegeliana do meio. Atividade determinada por finalidades, meio e conceito. 28/11/2019, p. 3. 


\section{Teleología y praxis en el Proceso de Trabajo}

Paso primordial para una valoración de la teleología del trabajo en Marx es establecer el marco referencial en que esta cuestión se sostiene en el Capital. En el Capítulo I Marx fija que el contexto de análisis de los procesos expuestos será el de la sociedad capitalista de producción esto es, no solo la producción de objetos en general si no, de mercancías. Lo cual implica un sistema específico de relaciones sociales. El análisis del proceso de trabajo debemos situarlo entonces en la línea lógica que ha cursado Marx desde el Primer Capítulo al ir determinando cada elemento de la mercancía como objeto.

Primeramente, Marx distingue en la mercancía su base material de realización, valor de uso, continente material de su capacidad de satisfacer externamente necesidades. El conjunto de las características materiales que permite que un objeto pueda satisfacer de forma específica una necesidad es la base determinante de su producción. Mas, la determinación de las condiciones capitalistas en las que surge la forma mercancía en cuanto objeto histórico específico están dadas por la indispensable expresión del objeto satisfactor en valor de cambio. Es decir, lo que hace del objeto satisfactor mercancía, es el momento en que no es objeto de consumo del productor sino, de intercambio. Por lo tanto el valor de cambio es la forma de realización de la mercancía en cuanto forma histórica de la sociedad capitalista. Antes de la sociedad capitalista se producían objetos útiles e incluso una parte de ello se dirigía al intercambio. Mas, es la sociedad capitalista donde el motivo del proceso de producción es el de producir objetos para el intercambio es decir, mercancías. Ello implica que las propiedades materiales del objeto, así como su cualidad objetiva de satisfacer necesidades son elementos secundarios, son condiciones materiales objetivas de su realización como mercancía, mas su fundamento esencial es el de realizar un proceso social de intercambio. En dicha sociedad por ejemplo pueden producirse objetos satisfactores de necesidades sin que estos encuentren forma de ser intercambiados por condiciones contextuales, mas estos objetos no podrán ser usados como valores de uso a pesar de sus excelentes condiciones materiales, o son intercambiados mercantilmente, o desaparecen. No es posible otra forma de consumo de estos valores de uso. 
Si tenemos este cuadro por base podremos comprender el proceso de producción dentro de este fundamento. El Capítulo $\mathrm{V}$ muestra el proceso de producción de mercancía como proceso de trabajo donde se expresa la naturaleza ya explicitada lógicamente en el Capítulo I. Por ello el fundamento socio histórico de una sociedad determinada al intercambio de lo producido, la extracción de lucro por vía de alienación de las condiciones del fundamento es una generalidad esencial que se expresará también en la demostración del proceso de trabajo. Proceso que implica la negación sistemática de las condiciones materiales, finitas de los valores de uso y del trabajo implicados en el proceso de intercambio. El fetichismo, con su reflexibilidad anti-aparencial, será no solo el fenómeno del ocultamiento de esa dinámica alienante si no el método para la explicitación de cada uno de sus momentos relacionales en el discurso teórico de Marx. En ese desarrollo el proceso de trabajo se explica de la siguiente forma:

El uso de la fuerza de trabajo es el trabajo mismo. El comprador de la fuerza de trabajo la consume haciendo trabajar a su vendedor. Con ello éste último llega a ser "actu" [efectivamente] lo que antes era sólo potentia [potencialmente]: fuerza de trabajo que se pone en movimiento a sí misma, obrero. ${ }^{15}$

En la primera frase del Capítulo V la fuerza de trabajo ya está explicitada en términos de una mercancía, Marx coloca primeramente cuál es su condición, su valor de uso material, dependiente de las condiciones objetivas y corporales del mismo: el trabajo. Esta solo puede realizarse a partir de la mediación del intercambio, esto es, la compra y uso por parte del capitalista que la gasta en el proceso de trabajo. Como señala Michael Heinrich lo que determina la esencialidad capitalista del proceso no es el tipo de objetos producidos o las actividades específicas en que esta es usada, si no el tipo de relación especifica en que se realiza $^{16}$. Si no se vende la fuerza de trabajo esta no se realiza como valor de uso, ello es el primer indicio de una sociedad divida por la especialización y la propiedad sobre los objetos de trabajo. Determinación que obliga a la venta por una parte de los sujetos productores de su capacidad de trabajar, su fuerza de trabajo. Este valor de uso, cuya condición (la existencia física del trabajador y del conjunto de

\footnotetext{
${ }^{15}$ MARX, K. El Capital: Crítica de la Economía Política. Madrid: Siglo XXI. 2010, p. 215. 16 HENRICH, Michael. Crítica de la economía política. Una introducción a El Capital de Marx. Escolar y Mayo Editores. 2008, p.68.
} 
relaciones antropológicas de reproducción del mismo) tiene la cualidad de producir nuevos valores de uso. El fundamento de la fuerza de trabajo es la producción de mediante el trabajo, (su valor de uso) de nuevos valores de uso. La determinación capitalista de este proceso sin embargo no está determinada de forma evidente en esta apariencia:

La producción de valores de uso, o bienes, no modifica su naturaleza general por el hecho de efectuarse para el capitalista y bajo su fiscalización. De ahí que en un comienzo debamos investigar el proceso de trabajo prescindiendo de la forma social determinada que asuma. ${ }^{17}$

En la línea de la reflexión hegeliana de la doctrina del aparecimiento observamos como la apariencia externa del proceso no determina suficientemente la esencia de la cosa. Por ello se encauza a la búsqueda de las propiedades que determinan la esencia del mismo. El trabajo es un proceso que caracteriza la existencia humana, más allá de las condiciones socio-históricas particulares. No obstante, no entraña ello un concepto absoluto, una naturaleza humana abstracta más allá de la existencia concreta de los individuos. Marx señala que es una condición material de posibilidad de los individuos. Este posicionamiento debemos enjuiciarlo desde una perspectiva lógica en la que la condición de inteligibilidad no puede derivar ni a la afirmación natural del trabajo como determinante de la acción humana, ni a la negación de su carácter de posibilidad material de la existencia por el desarrollo socio histórico especifico que este adopte en la actualidad. Marx inicia la explicitación de esta condición de posibilidad, la demostración de las determinaciones del proceso de trabajo. Inicialmente este es un proceso de transformación del medio natural. Espectro en el que el trabajo es un proceso de exteriorización de una finalidad subjetiva a partir de un medio. La realización de la finalidad del hombre que al ser subjetiva implica metabólicamente su relacionar con un objeto exterior, la naturaleza. Mas, ello solo es puesto momentáneamente pues la relación entre el hombre y la naturaleza mediada por el trabajo es una relación constitutiva. Por ello en esta perspectiva objeto y sujeto se encuentran en un plano práxico donde no puede oponerse lo humano y lo natural como esferas que se excluyen. Dice Marx:

${ }_{17}$ MARX, K. El Capital: Crítica de la Economía Política. Madrid: Siglo XXI. 2010, p. 215. 
El trabajo es, en primer lugar, un proceso entre el hombre y la naturaleza, un proceso en que el hombre medía, regula y controla su metabolismo con la naturaleza. El hombre se enfrenta a la materia natural misma como un poder natural. Pone en movimiento las fuerzas naturales que pertenecen a su corporeidad, brazos y piernas, cabeza y manos, a fin de apoderarse de los materiales de la naturaleza bajo una forma útil para su propia vida. $\mathrm{Al}$ operar por medio de ese movimiento sobre la naturaleza exterior a él y transformarla, transforma a la vez su propia naturaleza. ${ }^{18}$

En esta lógica el trabajo no es nunca una actividad que opone subjetividad y objeto. La acción finalistica del trabajo, hace parte de un ciclo de existencia natural del individuo y este de la existencia del medio. No hay en ello oposición entre la esfera cultural de la acción humana y la naturaleza como objeto a ser dominado, explotado ${ }^{19}$. Una base cosmogónica como esta supone entonces que las instancias de trabajo tampoco pueden establecerse como una naturaleza determinante de los procesos subjetivos. Sistema en el que la conciencia y los procesos conscientes serian un efecto, reflejo imperfecto de la objetividad de las relaciones establecidas en el medio natural de las relaciones de trabajo. Proceso que es al mismo tiempo natural y subjetivo. No existe un objeto pasivo que debe recibir la acción del sujeto consciente por el contrario, el propio trabajador es un espacio de cambio del contexto que transforma. No es menor esa dialéctica de transformación frente a las visiones que por el contrario desde un materialismo economicista invierten la ecuación y determinan la subjetividad de una exterioridad natural expresada en las relaciones de trabajo ${ }^{20}$. O al mismo tiempo sirve para comprender la limitación de la crítica estructuralista al humanismo marxiano, al suponer en el trabajo una estructura que elimina al sujeto²1. Marx es rotundo cuando coloca como preterido el momento de una finalidad subjetiva antepuesta a la realidad objetual exterior:

La situación en que el obrero se presenta en el mercado, como vendedor de su propia fuerza de trabajo, ha dejado atrás, en el trasfondo lejano de los tiempos primitivos, la situación en que el trabajo humano no se había despojado aún de su primera forma instintiva. Concebimos el trabajo bajo una forma en la cual pertenece exclusivamente al hombre. Una araña ejecuta operaciones que recuerdan las del tejedor, y una abeja avergonzaría, por la construcción de las celdillas de su panal, a más de un maestro

\footnotetext{
18 MARX, K. El Capital: Crítica de la Economía Política. Madrid: Siglo XXI. 2010, p. 215.

19 HARVEY, David. Para entender O Capital. São Paolo: Boitempo, 2013, p. 113.

20 KOHAN, Néstor; GOPEGUI, Belén. Nuestro Marx. La Oveja Roja, 2013.

${ }^{21}$ ALTHUSSER, Louis. Lire le Capital. Quadrige, Paris, 1996.
} 
albañil. Pero lo que distingue ventajosamente al peor maestro albañil de la mejor abeja es que el primero ha modelado la celdilla en su cabeza antes de construirla en la cera. ${ }^{22}$

La concepción del proceso de trabajo en estos términos ya no hace parte de un ser genérico, una antropología humana superior ${ }^{23}$. Por el contrario, es una dinámica de trasformación continua y no contingente, es propia de la existencia del ser humano. Mas en este momento el trabajo es una relación intencional que implica un proceso metabólico consciente. La diferenciación de la acción humana implica el desarrollo de una finalidad subjetiva que al exteriorizarse se determina. El trabajo parte del desarrollo de una finalidad subjetiva que es concebida mas que tiene su realización en el proceso de exteriorización. El trabajo realizado es una causa que tiene en su efecto la unidad de la causa ${ }^{24}$. Esta el trabajo es una dinámica praxica donde la acción material, natural, de la trasformación incluye de forma no contingente la determinación consciente. La actividad orientada a una finalidad es la realización de un concepto subjetivo que se determina al exteriorizarse y en esa exteriorización se une a su generación subjetiva. Dice Marx:

El proceso se extingue en el producto. Su producto es un valor de uso, un material de la naturaleza adaptado a las necesidades humanas mediante un cambio de forma. El trabajo se ha amalgamado a su objeto. Se ha objetivado, y el objeto ha sido elaborado. Lo que en el trabajador aparecía bajo la forma de movimiento, aparece ahora en el producto como atributo en reposo, bajo la forma del ser. El obrero hiló, y su producto es un hilado. ${ }^{25}$

Es clara que la distancia entre el planteo de Hegel y el de Marx es que aquí la acción teleológica existe en un cuerpo que se transforma materialmente. La materialidad del proceso por demás no niega de forma naturalista el momento consciente o subjetivo. Por el contrario, la salida a la tautología de la causa se soluciona al comprender la relación social de la que hace parte el proceso de trabajo. Cuando se introduce la relación entre obrero y capitalista como consumidor de la fuerza de trabajo se entiende que no hay una tautología de la finalidad subjetiva. El

\footnotetext{
22 MARX, K. El Capital: Crítica de la Economía Política. Madrid: Siglo XXI. 2010, p. 216.

23 HARVEY, David. Para entender O Capital. São Paolo: Boitempo, 2013, p. 114.

24 Aquí la antinomia de la finalidad en el pensamiento de Hegel tiene la solución en un proceso social. El trabajo sería un fin que: "si tiene que enunciarse acerca de él su verdad, puede expresarse solo de una fuerza que se solicita a sí misma hacia la externalización, o como una causa que es causa de sí misma, o cuyo efecto es de inmediato la causa."

25 MARX, K. El Capital: Crítica de la Economía Política. Madrid: Siglo XXI. 2010, p. 217.
} 
resultado del proceso de trabajo no es la simple realización de la finalidad subjetiva si no la realización de la fuerza de trabajo como mercancía. Esto es, el efecto de la finalidad es en sí una causa alterada, imagen superior de sí. El proceso de trabajo señala claramente que toda mercancía es en sí efectividad de un proceso social. La mercancía es la célula en la que se expresan de forma mediada las relaciones de tipo social que determinan el proceso de trabajo como proceso de valorización. Una mercancía no solo puede ser un objeto útil, que con base en sus características naturales determina la satisfacción de necesidades particulares. Ella es esencialmente la expresión material del trabajo acumulado, muerto y el trabajo vivo, valor de uso consumido de la fuerza de trabajo ${ }^{26}$.

Lamidas por el fuego del trabajo, incorporadas a éste, animadas para que desempeñen en el proceso las funciones acordes con su concepto y su destino, esas cosas son consumidas, sin duda, pero con un objetivo, como elementos en la formación de nuevos valores de uso, de nuevos productos que, en cuanto medios de subsistencia, son susceptibles de ingresar al consumo individual o, en calidad de medios de producción, a un nuevo proceso de trabajo. ${ }^{27}$

Es evidente que en esta concepción de la finalidad no se encuentra ya al nivel de una finalidad subjetiva en los términos hegelianos. Aquí la finalidad subjetiva contiene una determinación auto-subsistente dada en la necesidad social que la mercancía debe satisfacer (finalidad de otro). Así como esta es el resultado de un trabajo acumulado y de la relación con otro productor. No se trata del trabajo simple de un individuo enfrentado al medio externo. Complejo proceso de intercambio natural y social de energías y trasformaciones que persigue la exposición del carácter socio-determinado del trabajo y, por tanto, regulable por los seres humanos $^{28}$. El proceso de trabajo ha eliminado la diferencia y exterioridad de la subjetividad y el objeto ${ }^{29}$. Aquí la finalidad no es una racionalidad que se opone a la fuerza natural que no tiene relación ordenada. Al contrario que en el modelo

\footnotetext{
${ }^{26}$ HENRICH, Michael. Crítica de la economía política. Una introducción a El Capital de Marx. Escolar y Mayo Editores. 2008, p. 69.

${ }^{27}$ MARX, K. El Capital: Crítica de la Economía Política. Madrid: Siglo XXI. 2010, p. 221.

28 ORSINI, Federico. A astúcia da razão, ou seja, a 'filosofia da técnica' de Hegel. POA: 28/10/2019. p.4.

${ }^{29}$ IBER, Christian. Elementos da Teoria Marxiana do Capitalismo: um comentario sobre o livro I de O Capital de Karl Marx [recurso eletrônico] / Christian Iber. -- Porto Alegre, RS: Editora Fi; EdiPUCRS, 2013, p. 233.
} 
hegeliano, en el que la fuerza racional es una astucia menor, frente al medio selvático indomable de lo natural, que debe ser reducido y doblegado.

No obstante, más allá de la distinción de la formulación de Marx la evaluación de esta herencia teleológica a nivel lógico es esencial. Esta visión praxica del proceso de trabajo ha sufrido las más diversas interpretaciones. Representa en muchos pensamientos un accidente dentro de la cientificidad del capital. Mas, el entendimiento marxiano al papel del momento subjetivo dentro del proceso de trabajo debe ser analizado a la luz del instrumental general de exposición general del capital. Esto es, no se supone que el ejemplo del arquitecto refiera el trabajo como hecho asilado individual en un teórico que ha dedicado parte de su obra a la crítica del pensamiento robinsoniano propio de la económica política clásica. Así como no puede obviarse que la máxima que guía su exposición es el sistema de relaciones dominantes en la sociedad capitalista. No se trata del productor individual si no del productor que se encuentra inserto en sistema de relaciones donde su fuerza de trabajo es una mercancía. La finalidad aquí es una causa que se expresa en su efecto como unidad y extrañamiento de si al mismo tiempo.

Es en este contexto donde la teleología del trabajo comprende que la materialidad del proceso es esencialmente social. La existencia de la realidad objetual, natural, exterior como materia prima, así como los procesos fisiológicos que determinan la necesidad no son los determinantes del proceso de producción capitalista. El carácter determinado del trabajo estriba en su esencia de praxis relacional que implica la acción práctica donde objeto y sujeto están mediados.

Es por ello que la comprensión teleológica aporta a Marx una base reflexiva que supera el iusnaturalismo30. Sin ello la teoría marxiana no estaría alejada de la determinación liberal del trabajo como realidad natural desde la cual se fundamenta todo el andamiaje que opone al sujeto individual frente a un mundo que no puede transformar. Por el contrario, Marx insiste en su teleología en una formulación del trabajo como hecho histórico, socialmente determinado, por tanto, modificable por los sujetos. La praxis marxiana desde esta tradición ahonda la relación dialéctica entre teoría y práctica y establecer el vínculo entre el hombre y la naturaleza como relación constituyente.

${ }^{30}$ KOHAN, Nestor. Marx en su (Tercer) mundo. Habana: Ciencias Sociales, 2003, p. 147. 


\section{Consideraciones finales}

La concepción hegeliana de la Finalidad Subjetiva inicia un decurso argumentativo de superación del mecanismo. Todavía de que en esta la finalidad se expresa de forma externa permite enunciar la relación entre sujeto y objeto de forma no exterior. La comprensión hegeliana sienta la base para una teleología del trabajo como auto-poiésis.

La comprensión marxiana del proceso de trabajo señala este como proceso de relación praxica donde la finalidad implica en la práctica la relación dialéctica con la teoría. La materialidad del proceso no esta en el carácter exterior de la realidad natural, si no en el carácter de determinación socio histórica del proceso trabajo. Dado este en el carácter social de la necesidad, así como en la presencia del trabajo acumulado como reacción histórica.

La relación reflexiva de la teleología del trabajo permite comprender la distancia de la concepción de Marx de las interpretaciones exteriorizantes del trabajo. Sin esta referencia la explicitación marxiana del proceso de trabajo puede ser reducida a un determinismo natural. Tal comprensión no sería distinta de la base ius-natural que Marx contesta y supera.

\section{Referencias}

ALTHUSSER, Louis. Lire le Capital. Quadrige, Paris,1996.

HARVEY, David. Para entender O Capital. São Paolo: Boitempo, 2013.

HEGEL Georg Wilhelm Friedrich. Ciencia Da Lógica: 2. A Doutrina da Essencia. Trad. Cristhian G. Iber; Federico Orsini. Petropolis, Rj: Vozes; Bragança Paulista, Sp: Editora Universitária São Francisco, 2017.

HENRICH, Michael. Crítica de la economía política. Una introducción a El Capital de Marx. Escolar y Mayo editores. 2008.

IBER, Christian. Elementos da Teoria Marxiana do Capitalismo: um comentario sobre o livro I de O Capital de Karl Marx [recurso eletrônico] / Christian Iber. Porto Alegre, RS: Editora Fi; EdiPUCRS, 2013.

IBER, A teoría do objeto na Lógica de Hegel. Teleologia I. Introdução à teleología. Observação prévia. POA, 2019/2, 07/10/2019. 
IBER, Christian. A teoria do objeto na Lógica de Hegel Teleologia III. A teoria hegeliana do meio. Atividade determinada por finalidades, meio e conceito. 28/11/2019.

KOHAN, Nestor. Marx en su (Tercer) mundo. Habana: Ciencias Sociales, 2003.

KOHAN, Néstor; GOPEGUI, Belén. Nuestro Marx. La Oveja Roja, 2013.

LUKACS, Georg. El Joven Hegel. Y los problemas del capitalismo. Trad. Manuel Sacristan. Barcelona: Ediciones Grijalbo, 1970.

MARX, K. El Capital: Crítica de la Economía Política. Madrid: Siglo XXI. 2010.

ORSINI, Federico. A astúcia da razão, ou seja, a 'filosofia da técnica' de Hegel. POA: 28/10/2019.

Recebido em: 11/02/2020.

Aprovado em: 17/03/2020. 